\title{
U.S. Department of Veterans Affairs
}

Public Access Author manuscript

Qual Health Res. Author manuscript; available in PMC 2015 April 29.

Published in final edited form as:

Qual Health Res. 2015 March ; 25(3): 417-425. doi:10.1177/1049732314553011.

\section{Health Care Employee Perceptions of Patient-Centered Care: A Photovoice Project}

Salva Najib Balbale, MS ${ }^{1}$, Stephanie Turcios, BS ${ }^{1}$, and Sherri L. LaVela, PhD, MPH, MBA ${ }^{1}$

${ }^{1}$ Center for Evaluation of Practices and Experiences of Patient-Centered Care, United States

Department of Veterans Affairs, Hines, Illinois, USA

\begin{abstract}
Given the importance of health care employees in the delivery of patient-centered care, understanding their unique perspective is essential for quality improvement. The purpose of this study was to use photovoice to evaluate perceptions and experiences around patient-centered care among Veterans Affairs (VA) health care employees. We asked participants to take photographs of salient features in their environment related to patient-centered care. We used the photographs to facilitate dialogue during follow-up interviews. Twelve VA health care employees across two VA sites participated in the project. Although most participants felt satisfied with their work environment and experiences at the VA, several areas for improvement were identified. These included a need for more employee health and wellness initiatives and a need for enhanced opportunities for training and professional growth. Application of photovoice enabled us to learn about employees' unique perspectives around patient-centered care while engaging them in an evaluation of care delivery.
\end{abstract}

\section{Keywords}

health care; health care professionals; photography / photovoice; quality improvement; research, qualitative

Patient-centered care involves tailoring health services around individual patient needs, providing high-quality comprehensive care, and fostering a healing environment for patients (Institute of Medicine, 2001; Kellerman \& Kirk, 2007). Prior studies have established a range of benefits of patient-centered care with respect to patient outcomes (Kaplan, Greenfield, \& Ware Jr, 1989; Lewin, Skea, Entwistle, Zwarenstein, \& Dick, 2001; Stewart et al., 2000; Weiner et al., 2013). In the Veterans Affairs (VA) Health Care System, several VA facilities are transitioning towards a patient-centered care model by implementing innovations that focus on patients as whole persons. These innovations include providing complementary and alternative therapies, and enhancing access to care and information (LaVela, Gering, Schectman, \& Weaver, 2012; LaVela et al., 2012).

Corresponding Author: Salva Najib Balbale, MS, Edward Hines Jr. VA Hospital, 5000 S. 5th Avenue (151H), Hines, IL 60141, USA, Salva.Balbale@va.gov; Phone: 708.202.5898; Fax: 708.202.2316.

Declaration of Conflicting Interests: The authors declared no potential conflicts of interests with respect to the research, authorship, and/or publication of this article. 
Health care employees play an integral role in the coordination and delivery of patientcentered care (Avgar, Givan, \& Liu, 2011; Bernabeo \& Holmboe, 2013). Successful implementation requires a motivated workforce with a range of competencies, and necessitates health care employees and systems to partner with patients to create a truly patient-centered experience (Aboumatar \& Cooper, 2013; Bergeson \& Dean, 2006; Bernabeo \& Holmboe, 2013; Epstein \& Street, 2011; Luxford, Safran, \& Delbanco, 2011). The impact of patient-centered care, moreover, extends beyond the patient level, affecting both health care employees and health systems (Avgar et al., 2011; Epstein \& Street, 2011; Luxford et al., 2011).

Avgar et al. (2011) found that greater use of patient-centered care practices was associated with lower employee turnover intentions, and improved care quality and delivery.

Additionally, improved employee job satisfaction is a precursor for building a patientcentered organization (Luxford et al., 2011) and increasing patient satisfaction (Rave et al., 2003; Shaller, 2007). Supportive work environments and a highly-engaged workforce are also linked with improved quality of patient-centered care and hospital performance, along with higher employee retention and job satisfaction (Leggat, Bartram, Casimir, \& Stanton, 2010; Lowe, 2012; Rathert \& May, 2007; Weinberg, Avgar, Sugrue, \& Cooney-Miner, 2013).

As the VA transitions to a patient-centered model of care, evaluating patient-centered care quality and delivery is essential for quality improvement. Health care employees can provide key information to help evaluate and improve patient-centered care (Bergeson \& Dean, 2006). Engaging employees in the evaluation of patient-centered care presents a strategy to advance care quality and delivery, while also ensuring that employees feel valued and empowered to be involved in the organization's overarching mission to provide high-quality care (Lowe, 2012; Shaller, 2007).

Photovoice represents an innovative approach to engage employees in patient-centered care evaluations. In this participatory method, participants are invited to take photographs of meaningful elements in their environment, such as objects, events, and places (Wang \& Burris, 1997; Wang, Yi, Tao, \& Carovano, 1998). Participant-generated photography is intended to stimulate dialogue and create a platform for participants to share their unique narrative around a particular topic (Baker \& Wang, 2006; Wang \& Burris, 1994).

Researchers have found photovoice to be beneficial in engaging and empowering participants, and extracting data that identify participants' needs and perceptions. Photovoice has been used successfully among health care employees and settings (Catalani \& Minkler, 2010; Goff, Kleppel, Lindenauer, \& Rothberg, 2013; Wyk \& Salmoni, 2013), but its use in understanding employees' perceptions of patient-centered care has not been explored.

Engaging health care employees to understand their unique perceptions around patientcentered care is essential to comprehensively evaluate and improve quality of care. In particular, photovoice might be a valuable and innovative tool to understand health care employee views around patient-centered care and engage employees in an evaluation of patient-centered care in the VA. 


\section{Methods}

\section{Design and Objectives}

The purpose of this project was to use photovoice to qualitatively explore perceptions and experiences among VA health care employees who work within VA facilities that have implemented patient-centered care initiatives. Specifically, we aimed to understand how health care employees conceptualize patient-centered care, identify the contextual drivers of these perspectives, examine the impact of patient-centered care on the employee work experience, and to assess the benefits of photovoice to explore employee perceptions of patient-centered care. We conducted this project as part of a quality improvement effort by VA health care facilities to evaluate and understand patient-centered care using participatory methods that explore employee perspectives.

\section{Setting}

Data were collected at two VA health care facilities that implemented various patientcentered innovations and initiatives since 2010. We recruited a convenience sample of 12 VA health care employees, who routinely interact with patients and their unique needs. We distributed flyers and invitation letters at each VA facility to invite employee participation.

\section{Data Collection}

Health care employees who were interested in participating attended a 30-minute informational orientation session held at their VA facility to learn about the project's purpose and procedures. All interested participants received a five megapixel digital camera, a two gigabyte secure digital memory card, training and instructions for participation. We provided ethical training and included instructions on photography content. Pictures containing people, faces and identifiable information were prohibited.

Employees who chose to participate were asked to take approximately 25-30 photographs that captured prominent features in their environment using the following three prompts:

- Take a photograph of an activity that you do, which you feel contributes to the delivery of patient-centered care.

- Take a photograph of something that shows how patient-centered care has either positively or negatively affected your work experience.

- Take a photograph of something, or an activity, where the VA is or is not incorporating patient-centered care.

We provided technical training to ensure all participants were comfortable with digital camera use. Participants were given four weeks to take the photographs. After the participants took their photographs, they returned the memory card to the evaluation team using VA business reply envelopes.

Participants who took photographs returned their memory cards to the evaluation team and were invited to participate in one-on-one, 30- to 60-minute follow-up interviews at their VA facility. Interviews were scheduled approximately eight weeks from the date of the 
orientation session. We designed a semi structured interview guide for use during follow-up interviews. We used the Social Ecological Model to develop the interview guide and explore individual-, environmental- and system-level factors (Stokols, 1996) shaping employees' views on patient-centered care and their work experiences. The photovoice evaluator and participant used the photographs to facilitate dialogue during each follow-up interview. The evaluator probed into the significance of each photograph to elicit detailed personal narratives about work-related experiences with and perceptions of patient-centered care.

\section{Data Analysis}

All employee interviews were audio-recorded and transcribed verbatim for analyses. Interview data were entered into NVivo qualitative analysis software version 8 (QSR International, Doncaster, Victoria, Australia) and an inductive coding approach was used for analysis. Two qualitative research experts conducted three rounds of coding to develop and finalize emerging themes. The two coders independently reviewed three transcripts to develop a preliminary code list in the first round. The coders generated a list of codes collaboratively and coded five transcripts independently and together refined the code definitions. The coders then applied a final list of codes to remaining transcripts. Coded transcripts were analyzed within and across cases to develop themes. The coders reconciled discrepancies through consensus.

\section{Results}

Twenty-two VA health care employees were approached for participation. Twelve employees $(n=12)$ across two VA sites participated in both phases of this photovoice project. The age range among employee participants was between 29 and 65 years. Ten participants (83.3\%) were men; two (16.7\%) were women. In total, participants took 337 photographs. The number of photographs taken ranged from 20 to 36 with an average of 27 photographs taken per participant. Positions held and departments represented by participants included VA clinicians, customer and support staff, non-clinical management, therapists and psychosocial workers, and facilities management and beautification. Clinicians included VA physicians, registered nurses and nurse practitioners. We categorized the qualitative data into emerging themes. Themes were subsequently organized into individual, environmental, and system levels, as described by the Social Ecological Model (Stokols, 1996). To systematically explore the key factors influencing employee perceptions of patient-centered care at multiple levels, we framed and presented the results by level.

\section{Individual Level}

VA employees perceived patient-centered care as viewing and treating the patient as a whole. Employees described patient-centered care as providing services that go above and beyond the patient's needs and having the necessary resources on hand to assist patients. Although perceptions of patient-centered care were described with the patient in mind, employee participants also noted the importance of job satisfaction and their own work experiences and contributions that help to create a patient-centered environment. 
Participants discussed the need for tailored treatment for each patient and an emphasis of putting patients first in their role at work. "All of us may not be Veterans and may not have the opportunity to come to the VA, but we have to learn how to treat each case on an individual basis," stated one clinician. A support staff member reflected on his photograph of a VA sign that read "Patient- and family-centered care," and said: "[Patients] are the number one priority.... I want to make sure they're well taken care of. I love this job."

A non-clinical manager commented on his photograph of decorative stones that each read "Live," "Heal," and "Grow" (Figure 1), drawing a connection with his own perception of patient-centered care. The participant stated:

In this picture ... is actually some rocks I had received when I was on travel for a trip. This kind of depicts how I feel about the things that really work in patientcentered care. Our objective really is to help patients live their life fully. And so once they begin to really live then they transition towards the healing process, where they really improve themselves. And then once you feel like you've been completely healed, and you've gotten through that process and you're able to really talk about it, then you grow because you're going to show other people exactly how to do it. So it's this continuous cycle of trying to make sure we provide them with what they need to live their lives fully. But then they go a step further to complete healing and then go into growing by showing others.

Most participants felt satisfied with their work environment and experiences at the VA, noting that working with the Veteran population was particularly satisfying. One clinician described a photograph of her work computer and desk, and said:

I have been here over twenty seven years, so my thing is ... it is not just a job. I enjoy what I am doing. I enjoy taking care of patients. Not only am I giving, I get something back.... It is a rewarding experience being in a service to take care of Veterans.... It is about giving back, for so many of them lost their lives and lost quality of care.

Another clinician commented on his photograph of a telephone and noted:

Oftentimes the effect of just listening to what [patients] have to say means the world because they have waited on line and in a cue or they have listened to automated voices. It's rewarding when you get someone to say "I just want to thank you for listening to me," because sometimes we are [patients'] social outlet as well.

Additionally, employees commented that working with other employees contributed positively to their individual work experiences. Participants described their photographs, including images of employee work spaces, computers, department bulletin boards and break rooms, to illustrate their individual work experiences. "I'm enjoying [my job] immensely, not just the interaction with the Veterans, but also all the employees that I've met. It's just a great group of people," said a customer support staff member.

\section{Environmental Level}

At the physical environmental level, participants discussed VA spaces and characteristics that impacted both their daily experience at work and patients' experiences when accessing 
VA health care services. Specific to employees' daily experiences in coming to the VA for work, one clinician referred to her photograph of a VA parking lot and stated: "The most negative thing is getting to work, having to fight traffic, and to fight parking. I don't like our parking situation at all. It is not customer friendly to the employees." Another clinician commented on his photograph of a meditation room designed for the VA community. The clinician noted the importance of a relaxing atmosphere to employees as well as patients: "[The meditation room] is a nice area just to sit and relax. They have the piano that plays by itself. The atmosphere there is very therapeutic. It is a tranquil environment. You can relax, both patients and the employees."

Participants also photographed physical attributes they felt were essential for the patient experience of patient-centered care. One psychosocial worker took a photograph of artwork in a hospital hallway (Figure 2), and discussed the impact of art and aesthetics in the health care environment. The participant said:

This is the artwork. Artwork in general in an environment really adds to the mood. But sometimes artwork in itself ... if put on a wall in a waiting area, can almost serve as something to focus on for guided imagery purposes. So really artwork, if it's picked correctly, serves dual purposes, and this adds to the actual overall healing environment.

Others commented on patient waiting areas and their impact on patients. One clinician photographed a patient waiting area and discussed the need for waiting rooms that were less crowded:

Sometimes the patient just needs a place to calm down and chill out before they even go in, because sometimes that [waiting] room can get crowded [and] you may have a few patients that just need serenity. Sometimes, it gives you a chance to calm down before you actually go into that room.

A support staff member commented on his photograph of a waiting room (Figure 3), indicating the need to create a comforting atmosphere in all patient waiting areas:

This is a waiting area.... And here it is all about the healing environment ... really looking at the overall healing space, and lighting of the space and how you can create a mood.... It's more of the idea of the total experience of the patient, which requires both clinical and administrative work.... It's about how we provide our service, because perception plays a huge role.

Participants generally responded positively to their social environment and interactions with patients and fellow employees. All participants felt that communicating respectfully with patients was paramount to patient-centered care, but some highlighted that communications within employee groups were equally important and, in some instances, could be improved. One clinician described the significance underlying his photograph of a picture collage of VA nurses and health care staff. "I think having a harmonious environment is essential ... in the overall mission of helping Veterans," commented the clinician in reference to working with other employees. 
Most participants also believed that a sense of camaraderie existed in delivering care for Veterans in the VA. One member of VA support staff reflected on his photographs depicting his coworkers' desks: "I love the people that I work with.... We all get along.... It is a family thing." Others noted a need for employees to proactively create a friendly, courteous atmosphere for each other. "'How are you feeling today?' and 'Thank you' is another thing, not only with the patients, but with other [employees]," reported another clinician on the need for courtesy in communicating with employees.

In interacting with other VA employees and departments, some participants reported challenges in bridging gaps across the VA departments to efficiently deliver patient care. These participants emphasized the need for solutions to reduce fragmentation and effectively meet patient needs. "That concept of working together — that's what it's all about—not 'You're not in my department.' It is supposed to be one VA and I think sometimes there is a disconnect here," commented one clinician. Others suggested that the best solution to this problem would be concerted efforts to improve communication and information sharing across departments.

One clinician reflected on his photograph of a VA sign indicating various hospital departments and their locations, and highlighted a need for mitigating workplace silos. The participant noted:

The other [issue] is breaking down the barriers within all of the silos in the VA.... Not everyone is sharing information and we are kind of divided. But in the few instances that we did share information and did try to break down barriers, it really did wonders for the employees.

Another clinician described his photograph of a VA conference room for employee meetings. The clinician posited that networking with other departments, and even other VAs, would be a useful practice:

Most of the people [who] work in patient-centered care ... have no clue there is all that information. That is where networking is so important ... talking about issues that other clinics had.... That is a great idea. It's called networking!

Participants discussed employee engagement in quality improvement and development of new patient-centered initiatives. In reference to a photograph of a program flyer inviting employees to generate innovative patient-centered care ideas, one non-clinical manager said:

We collect [ideas for] patient-centered care initiatives every year from staff members. We then compile that list, prioritize them ... and we decide to adopt certain initiatives that were submitted by the individuals, and they get praised.... So it kind of breeds competition but also makes [employees] think creatively. It gets them involved in the process, which is important because you can't sustain a culture if you don't find a way to engage and excite the people at the grassroots [level].

\section{System Level}

Participants discussed several factors at the system and organizational level that impact their perspective around patient-centered care. These included their thoughts on the VA care 
system overall, resources provided to help employees successfully do their jobs and health and wellness initiatives designed for employees. One psychosocial worker referred to a photograph of a large VA plaque that read "Where Courage Meets Compassion," and reflected broadly on patient care delivered in the VA system:

At the VA, we've upgraded so much. A lot of the different things that they have done, it is all centered around the patient. I think that they have improved a lot.... I have been here for a long time and have actually seen progress in care, the way we care for our patients, and the way we perceive the care that we give to our patients.... You actually do it and you enjoy the interactions with the patients.

Employee participants also noted the importance of employee resources that promote job satisfaction and help create a patient-centered environment. These included opportunities for training and education for professional growth, access to technology, and leadership support. Referring to a photograph of a flyer for a VA employee training event, one non-clinical manager stated that leadership support and employee education and engagement initiatives were critical for patient-centered care implementation:

The first thing I would say is [that] leadership support and employee education is a must... You can't do anything without them. We need a little more than just coming to work and [employees] really want to learn ... want to grow and build their professional skill sets. So our educational events engage our employees and push them to be more than just an employee.

One clinician reflected on a photograph depicting a VA clinic reception desk and stated:

We're here for Veterans, but we have to remember to take care of our employees. We have to make sure that they are treated properly, that they get what is due in terms of appreciation. I think educating employees is the important part.... We need to put our focus into people that are most important. It's front line office staff, the doctors, the residents, the assistants. If [the VA is] able to do that, things are going to run a lot smoother.

Resources and programs to enhance employee health and wellness were central to the employee experience. A psychosocial worker commented on his photograph of physical activity equipment designed for patients:

We don't have a gym facility here, they have [exercise] apparatuses but unless you are patient you don't have access to those.... I think they should have [a gym] nearby, something convenient.... When [employees] are here, they come into work a little early, get your workout and then proceed onto work right afterward.

One clinician took a photograph of a mile marker along a walking path designed for VA employees and patients (Figure 4). The participant reflected on employee wellness programs that helped improve employees' health, and also helped in bridging gaps between employees:

[Our CEO] had a walk program. It was a hospital-wide ... employee-oriented group exercise. We could either walk or run ... I was in charge of the joggers and he was in charge of the walkers. You felt like it broke down barriers. I mean it was great 
seeing our CEO walk with the employees ... A sense of unity. It allows staff to be a lot more comfortable about where they work. It makes you believe that we are a family, which is what we try to talk about with patient-centered care.

\section{Using Photovoice: Employee Feedback}

We received a positive response among employees regarding the use of photovoice to explore employee perceptions around patient-centered care. Many participants felt that the project was a unique and creative way to understand the employee viewpoint, and said that they would be willing to participate in such a project again. One psychosocial worker commented:

I feel like I get a chance to explain my side of the VA.... [It was] an opportunity to share the experience. The pictures are worth a thousand words. Sometimes when you can't say it all in words, you can say it in pictures ... because you can see. Then you can make a judgment on what you see more than what you hear.

Employees reported that participating in the photovoice project gave them the opportunity to reflect on their job experience and satisfaction, and helped them recognize how it plays a significant role in the patient-centered care model. Others reflected on the overall VA environment, and how they felt patient-centered care fit in. One customer support staff member stated:

As I started thinking about it, there's just so much that's patient centered care, that [taking pictures] was really quite easy, because, as I look around, I think this VA facility is what it's primarily there for. I could have taken so many more pictures.

Another clinician noted:

[Participating in this project] helped me. I was thrilled to come here today ... to talk about maybe one of the directions [the VA] should go in. I think patientcentered care is great, I think what we are doing is fine ... but taking the pictures allowed me to focus; it allowed me to focus on the positive which I think is good, because we have done a lot of good things here in this hospital.

Participants also felt that their individual feedback could be helpful in stimulating greater changes and improvements in the VA. One support staff member stated:

As I got involved in [the project], I started looking at how beneficial I can be with my input on something bigger than myself.... It felt good doing something positive and being included on something like this. Maybe opinions combined might change something later on down a bit. So I feel good about it.

\section{Discussion}

Successful implementation of patient-centered care is designed to improve not only patient outcomes, but also employee and organizational outcomes (Avgar et al., 2011; Epstein, Fiscella, Lesser, \& Stange, 2010; Rathert \& May, 2007). Given the importance of health care employees in the delivery of patient-centered care, engaging employees, obtaining their buy-in, and understanding their unique perspectives are essential components for evaluation 
and quality improvement (Lowe, 2012; Wakefield et al., 1994). Qualitative examinations of the employee viewpoint of patient-centered care, however, have been limited.

Application of the photovoice methodology enabled us to learn about employees' unique perspectives around patient-centered care in the VA while engaging them in the evaluation process. Our findings uniquely contribute to existing literature around health care employee perceptions, needs and experiences as they relate to health care delivery, and can be incorporated into patient-centered innovations and care design strategies that account for the needs of employees as well as patients.

Using photovoice and participatory methodologies in the area of patient-centered care is a new approach (Lorenz \& Chilingerian, 2011). We found its application in this project to be valuable for several reasons. In using photovoice, we created an innovative forum to better understand the employee perspective on patient-centered care, and allowed participants to creatively and effectively describe their perceptions and experiences. Furthermore, we found that photovoice was useful in identifying specific needs, preferences and values that drive employee perspectives. Finally, we found that photovoice was helpful in facilitating discussion and engaging employees in qualitatively evaluating patient-centered care in the VA.

Employees perceived patient-centered care as an approach to treat patients holistically and provide services that go above and beyond patient needs. They also discussed their role in the VA and its relationship with patient-centered care, highlighting that employees at all levels of the organization had to be engaged in the concept of patient-centered care to fully implement it. Many believed that employee education, training, and access to the necessary resources to assist patients were important tools for employees to help deliver patientcentered care. These factors are consistent with the system and employee attributes needed to create a patient-centered care environment (Aboumatar \& Cooper, 2013; Bergeson \& Dean, 2006; Bernabeo \& Holmboe, 2013).

Improving employee-level outcomes can, in turn, yield improved outcomes for patients and the organization's quality of care (Avgar et al., 2011; Lowe, 2012; Rathert \& May, 2007; Rave et al., 2003). Although most employees in our sample were satisfied with their jobs and work experiences, participant photography and interview data presented specific areas where employee experiences can be improved. These included a need for more employee health and wellness initiatives as well as a need for enhanced opportunities for employee training and professional growth. As indicated by previous findings, providing employees with a supportive work environment and addressing their needs is a preliminary step for quality improvement (Rathert \& May, 2007; Shaller, 2007; Weinberg et al., 2013).

The VA health care employee workforce was vital in the organization's prior efforts to transform its health care system and improve quality of care (Jha, Perlin, Kizer, \& Dudley, 2003; Kizer \& Dudley, 2009). As the VA now moves toward implementing a patientcentered model of care, employee engagement and high performance are important prerequisites. Our findings indicated that VA employees are generally dedicated and enthusiastic to be involved in the VA's mission to provide Veterans with patient-centered 
care. Organizations should harness this enthusiasm among highly-engaged employees to advance their mission, and should facilitate targeted efforts to promote buy-in from employees who are less engaged. As demonstrated previously, improving quality of care and employee performance depends on sustaining a sense of engagement among employees in the organization's overarching goals (Lowe, 2012).

This study had several limitations. Our findings were based on a small sample size and a limited number of health care employee occupations. Although this allowed for detailed and in-depth examination, we might not have accurately represented the perspectives found in the overall VA health care employee population. Additionally, employee views and perceptions were explored at a single point of time using a cross-sectional design; changes in their views over time were not explored.

Additional limitations associated with photovoice might have been introduced (Wang \& Burris, 1994, 1997). In particular, training instructions provided at the orientation session might have influenced participants' photography. Finally, the data collection period spanned two months, and participants were unable to comment on their photographs for several weeks after taking them. As a result, some participants might have been unable to recall or accurately convey the intended meaning of their photographs during follow-up interviews.

Developing a health care workforce that is committed to patient-centered care involves creating a supportive work environment for employees and engaging them in the design, implementation and evaluation of patient-centered care processes (Leggat et al., 2010; Lowe, 2012; Rathert \& May, 2007; Shaller, 2007). Health care employees should be vital in the evaluation of patient-centered care as their perspectives and experiences can provide important information for quality improvement, and their engagement can stimulate improvements in care quality. Additional qualitative studies are needed that go beyond conventional methods to engage employees as partners with evaluators to develop enhanced strategies for evaluation and quality improvement. Partnering with employees is an important opportunity to inform quality improvement, and aligns with the fundamental patient-centered care vision to provide high-quality patient care, while also yielding positive outcomes for employees and health systems.

Using photovoice enhanced our understanding of VA health care employees' perspectives around patient-centered care in the VA. We identified three categories of factors driving employee perceptions: (a) individual-level factors, including employee work experiences, job satisfaction and commitment to delivering patient-centered care, (b) environmental-level factors, including VA facility aesthetics and physical attributes, as well as interactions with other employees and (c) system-level factors, including resources and programs designed to improve employee wellness, job satisfaction and professional growth. Our application of photovoice was effective in engaging health care employees in a discussion around patientcentered care and developing a foundation for quality improvement.

\section{Acknowledgments}

The views expressed in this manuscript are those of the authors and do not necessarily reflect the position or policy of the Department of Veterans Affairs. 
Funding: The authors disclosed receipt of the following financial support for the research, authorship and/or publication of this article: Funding was received from the Department of Veterans Affairs, Office of PatientCentered Care and Cultural Transformation and the Office of Research and Development Health Services Research and Development, Quality Enhancement Research Initiative (PCE-13-002).

\section{References}

Aboumatar HJ, Cooper LA. Contextualizing patient-centered care to fulfill its promise of better health outcomes: Beyond who, what, and why. Annals of Internal Medicine. 2013; 158(8):628629.10.7326/0003-4819-158-8-201304160-00008 [PubMed: 23588750]

Avgar AC, Givan RK, Liu M. Patient-centered but employee delivered: Patient care innovation, turnover, and organizational outcomes in hospitals. Industrial and Labor Relations Review. 2011; 64(3):424-440. Retrieved from http://digitalcommons.ilr.cornell.edu/ilrreview.

Baker TA, Wang CC. Photovoice: Use of a participatory action research method to explore the chronic pain experience in older adults. Qualitative Health Research. 2006; 16(10):14051413.10.1177/1049732306294118 [PubMed: 17079801]

Bergeson SC, Dean JD. A systems approach to patient-centered care. JAMA: The Journal of the American Medical Association. 2006; 296(23):2848-2851.10.1001/jama.296.23.2848

Bernabeo E, Holmboe ES. Patients, providers, and systems need to acquire a specific set of competencies to achieve truly patient-centered care. Health Affairs. 2013; 32(2):250-258.10.1377/ hlthaff.2012.1120 [PubMed: 23381517]

Catalani C, Minkler M. Photovoice: A review of the literature in health and public health. Health Education \& Behavior. 2010; 37(3):424-451.10.1177/1090198109342084 [PubMed: 19797541]

Epstein RM, Fiscella K, Lesser CS, Stange KC. Why the nation needs a policy push on patientcentered health care. Health Affairs. 2010; 29(8):1489-1495.10.1377/hlthaff.2009.0888 [PubMed: 20679652]

Epstein RM, Street RL. The values and value of patient-centered care. The Annals of Family Medicine. 2011; 9(2):100-103.10.1370/afm.1239

Goff SL, Kleppel R, Lindenauer PK, Rothberg MB. Hospital workers' perceptions of waste: a qualitative study involving photo-elicitation. BMJ Quality \& Safety. 201310.1136/ bmjqs-2012-001683

Institute of Medicine. Committee on Quality of Health Care in America. Crossing the quality chasm: A new health system for the 21st century. National Academies Press; 2001. Retrieved from http:// www.iom.edu/Reports/2001/Crossing-the-Quality-Chasm-A-New-Health-System-for-the-21stCentury.aspx

Jha AK, Perlin JB, Kizer KW, Dudley RA. Effect of the transformation of the Veterans Affairs Health Care System on the quality of care. New England Journal of Medicine. 2003; 348(22):22182227.10.1056/NEJMsa021899 [PubMed: 12773650]

Kaplan SH, Greenfield S, Ware JE Jr. Assessing the effects of physician-patient interactions on the outcomes of chronic disease. Medical Care. 1989; 27(3):S110. [PubMed: 2646486]

Kellerman R, Kirk L. Principles of the patient-centered medical home. American Family Physician. 2007; 76(6):774-775. [PubMed: 17910291]

Kizer KW, Dudley RA. Extreme makeover: transformation of the Veterans health care system. Annual Review of Public Health. 2009; 30:313-339.10.1146/annurev.publhealth.29.020907.090940

LaVela SL, Schectman G, Gering J, Locatelli SM, Gawron A, Weaver FM. Understanding health care communication preferences of veteran primary care users. Patient education and counseling. 2012; 88(3):420-426.10.1016/j.pec.2012.06.004 [PubMed: 22766452]

LaVela SL, Gering J, Schectman G, Weaver FM. Optimizing primary care telephone access and patient satisfaction. Evaluation \& the health professions. 2012; 35(1):7786.10.1177/0163278711411479 [PubMed: 21685222]

Leggat SG, Bartram T, Casimir G, Stanton P. Nurse perceptions of the quality of patient care: Confirming the importance of empowerment and job satisfaction. Health Care Management Review. 2010; 35(4):355-364.10.1097/HMR.0b013e3181e4ec55 [PubMed: 20844360] 
Lewin SA, Skea ZC, Entwistle V, Zwarenstein M, Dick J. Interventions for providers to promote a patient-centred approach in clinical consultations. Cochrane Database of Systematic Reviews. 2001; 4(10)10.1002/14651858.CD003267

Lorenz LS, Chilingerian JA. Using visual and narrative methods to achieve fair process in clinical care. Journal of visualized experiments: Journal of Visualized Experiments. 2011; 16(48):23422348.10.3791/2342

Lowe G. How employee engagement matters for hospital performance. Healthcare Quarterly. 2012; 15(2):29-39. [PubMed: 22688203]

Luxford K, Safran DG, Delbanco T. Promoting patient-centered care: a qualitative study of facilitators and barriers in healthcare organizations with a reputation for improving the patient experience. International Journal for Quality in Health Care. 2011; 23(5):510-515.10.1093/intqhc/mzr024 [PubMed: 21586433]

NVivo qualitative data analysis software (Version 8). Doncaster, Victoria, Australia: QSR International; Computer software

Rathert C, May DR. Health care work environments, employee satisfaction, and patient safety: Care provider perspectives. Health Care Management Review. 2007; 32(1):2-11. [PubMed: 17245197]

Rave N, Geyer M, Reeder B, Ernst J, Goldberg L, Barnard C. Radical systems change: Innovative strategies to improve patient satisfaction. The Journal of Ambulatory Care Management. 2003; 26(2):159-174. [PubMed: 12698930]

Shaller, D. Patient-centered care: what does it take?. Commonwealth Fund. 2007. Retrieved from http://www.commonwealthfund.org

Stewart M, Brown JB, Donner A, McWhinney IR, Oates J, Weston WW, Jordon J. The impact of patient-centered care on outcomes. The Journal of Family Practice. 2000; 49(9):796-804. [PubMed: 11032203]

Stokols D. Translating social ecological theory into guidelines for community health promotion. American Journal of Health Promotion. 1996; 10(4):282-298.10.4278/0890-1171-10.4.282 [PubMed: 10159709]

Wakefield DS, Cyphert ST, Murray JF, Uden-Holman T, Hendryx MS, Wakefield BJ, Helms CM. Understanding patient-centered care in the context of total quality management and continuous quality improvement. The Joint Commission Journal on Quality Improvement. 1994; 20(3):152. [PubMed: 8032429]

Wang C, Burris MA. Empowerment through photo novella: Portraits of participation. Health Education \& Behavior. 1994; 21(2):171-186.10.1177/109019819402100204

Wang C, Burris MA. Photovoice: Concept, methodology, and use for participatory needs assessment. Health Education \& Behavior. 1997; 24(3):369-387. [PubMed: 9158980]

Wang CC, Yi WK, Tao ZW, Carovano K. Photovoice as a participatory health promotion strategy. Health Promotion International. 1998; 13(1):75-86.10.1093/heapro/13.1.75

Weinberg DB, Avgar AC, Sugrue NM, Cooney-Miner D. The Importance of a High-Performance Work Environment in Hospitals. Health Services Research. 2013; 48(1):319-332.10.1111/j. 1475-6773.2012.01438.x [PubMed: 22716770]

Weiner SJ, Schwartz A, Sharma G, Binns-Calvey A, Ashley N, Kelly B, et al. Harris I. PatientCentered Decision Making and Health Care OutcomesAn Observational Study. Annals of Internal Medicine. 2013; 158(8):573-579.10.7326/0003-4819-158-8-201304160-00001 [PubMed: 23588745]

Wyk PMV, Salmoni A. Using photovoice to identify patient transfers risk factors in long-term care home settings. International Journal of Human Factors and Ergonomics. 2013; 2(1):4965.10.1504/IJHFE.2013.055992

\section{Biographies}

Salva N. Balbale, MS, is a social science research analyst in the Center for Evaluation of Practices and Experiences of Patient-Centered Care within the Department of Veterans Affairs. 
Stephanie Turcios, BS, is a research assistant in the Center for Evaluation of Practices and Experiences of Patient-Centered Care within the Department of Veterans Affairs.

Sherri L. LaVela, PhD, MPH, MBA, is the director of the Center for Evaluation of Practices and Experiences of Patient-Centered Care within the Department of Veterans Affairs, and an assistant professor in the Center for Healthcare Studies at Northwestern University. 


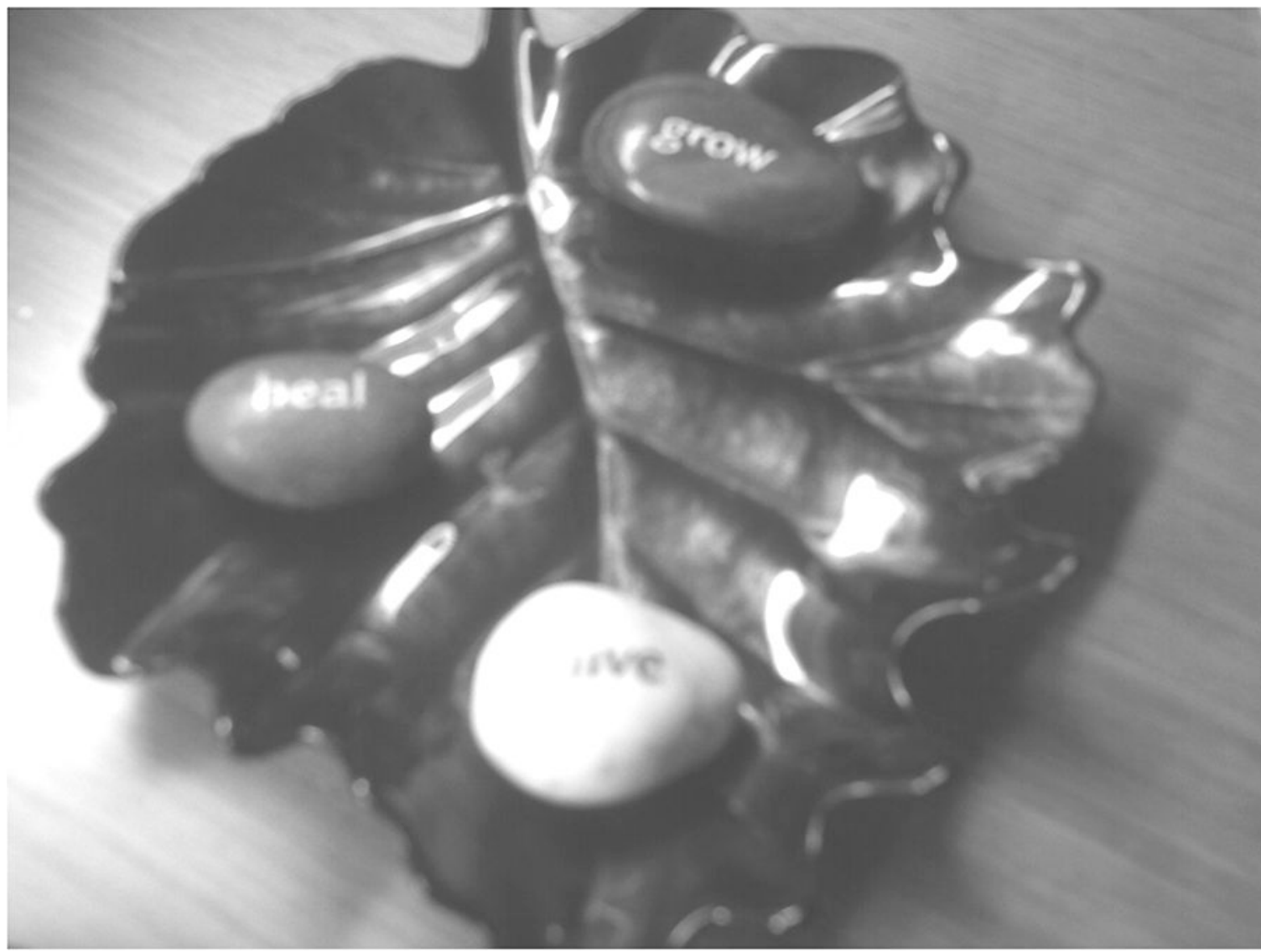

Figure 1. Photograph of decorative stones that read: "Live," "Heal," and "Grow"

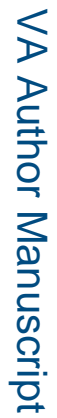




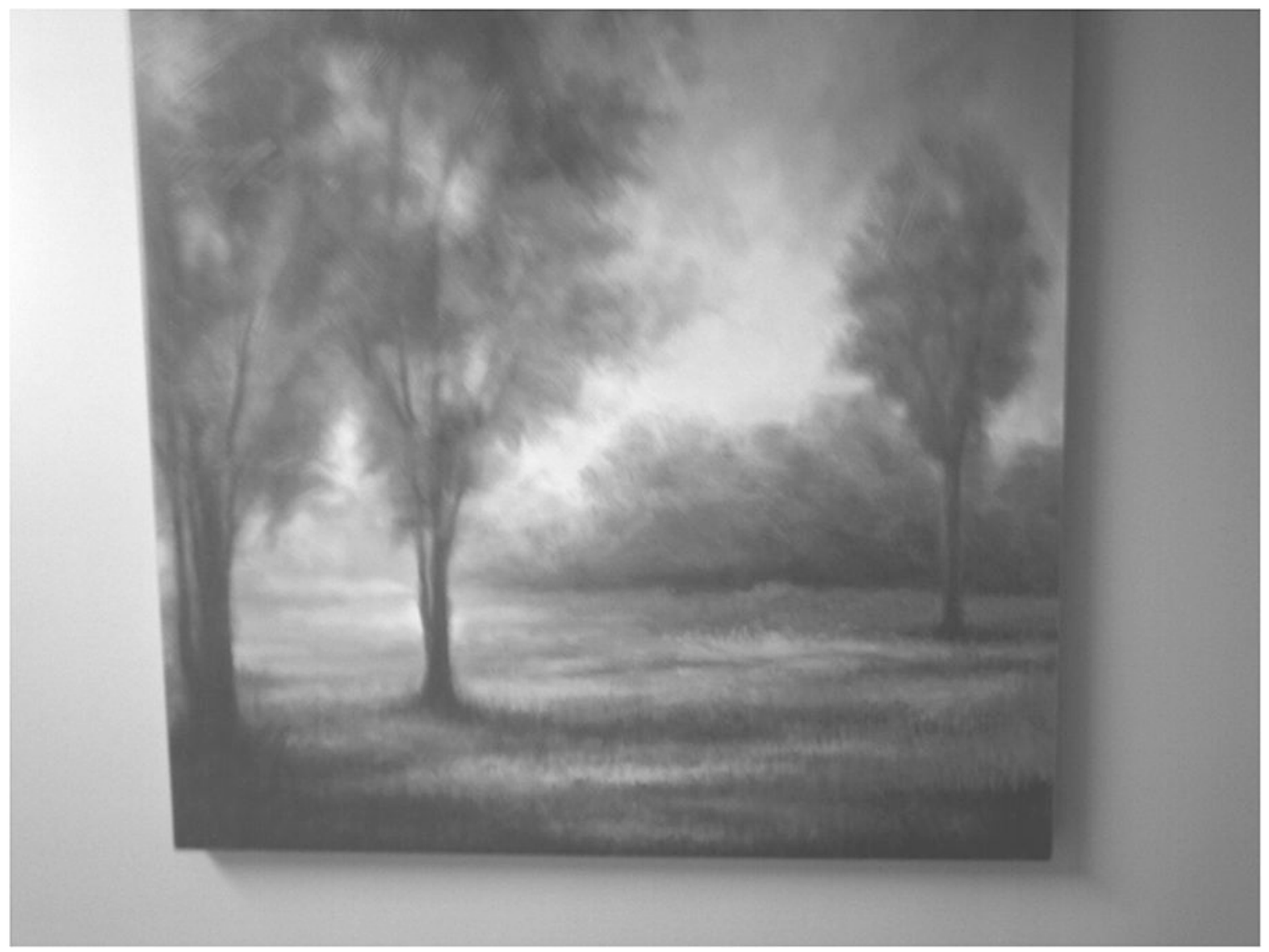

Figure 2. Photograph of hallway artwork

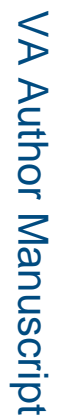




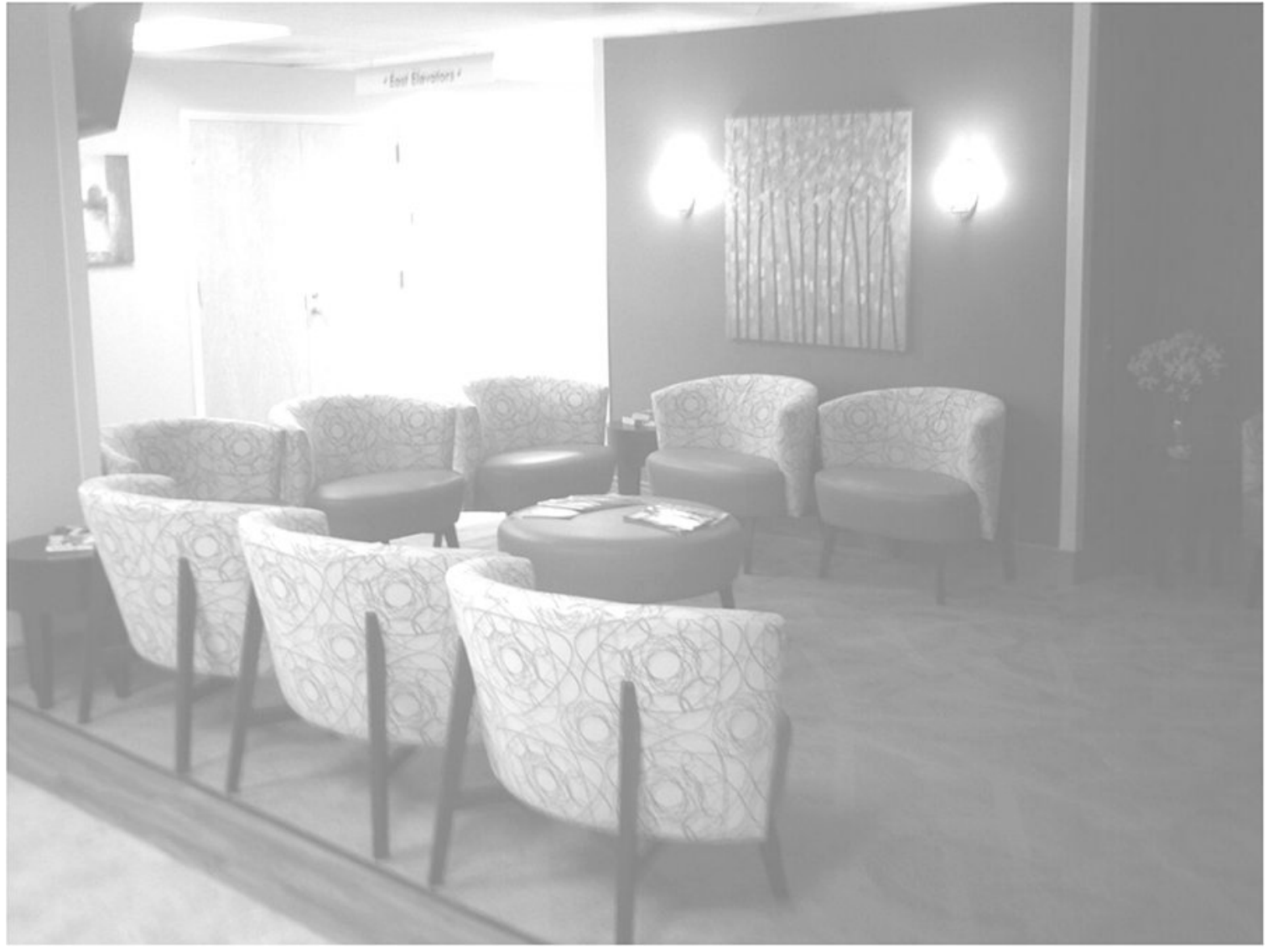

Figure 3. Photograph of a patient waiting area

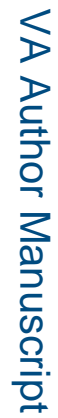




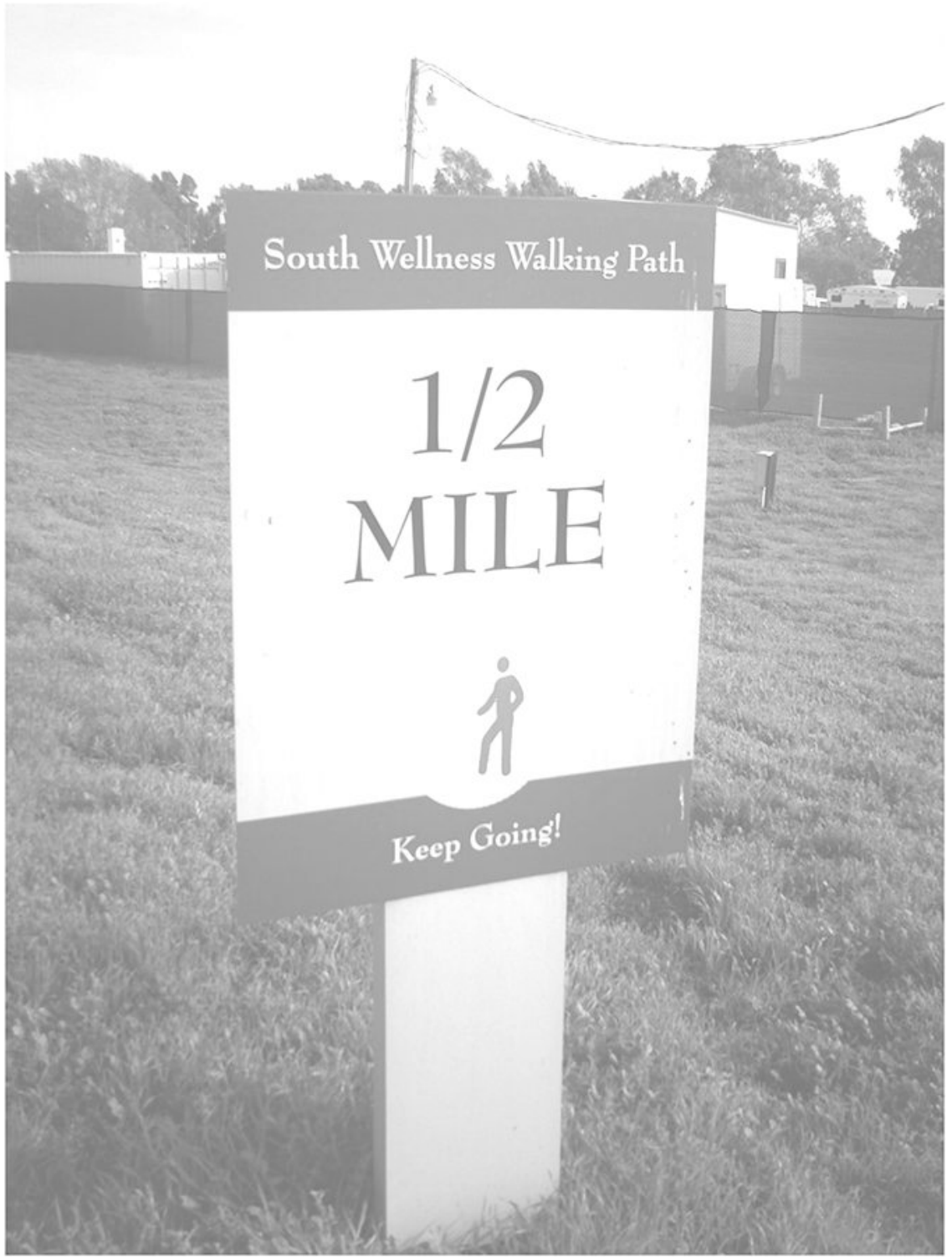

Figure 4. Photograph of a walking path mile marker sign 